\title{
SIKAP REMAJA PUTRI TENTANG DETEKSI DINI KANKER PAYUDARA DENGAN SADARI (Studi Kasus di Kelas X dan XI SMAN 1 Pangkalan Bun Kabupaten Kotawaringin Barat Provinsi Kalimantan Tengah)
}

\author{
${ }^{1} J e n n y$ Oktarina \\ ${ }^{1}$ STIKes Borneo Cendekia Medika \\ ${ }^{1}$ Email oktarina.jenny@yahoo.co.id
}

\begin{abstract}
ABSTRAK
Masih kurangnya kesadaran wanita Indonesia dalam melakukan deteksi dini kanker payudara, bahkan masih banyak wanita Indonesia belum mengetahui cara deteksi dini kanker payudara yang menjadi salah satu penyebabkan angka kejadian kanker payudara cukup besar selain dari faktor gaya hidup yang tidak sehat. Pemeriksaan sederhana untuk mendeteksi secara dini berubahan yang terjadi pada payudara yaitu dengan memeriksa payudara sendiri atau disebut dengan istilah sadari.Tujuan penelitian mengidentifikasi sikap remaja putri tentang deteksi dini kanker payudara dengan SADARI. Studi pendahuluan yang dilakukan di SMAN 1 Pangkalan Bun.

Desain penelitian adalah deskriptif. Populasi remaja putri di kelas $\mathrm{X}$ dan XI SMAN 1 Pangkalan Bun kabupaten kotawaringin barat provinsi kalimantan tengah berjumlah 92 orang dengan sampel 92 responden. Teknik sampling menggunakan total sampling. Variabelnya sikap remaja putri tentang deteksi dini kanker payudara dengan SADARI, instrumen yang digunakan pada penelitian ini adalah kuesioner, dengan pengolahan data melalui tahapan editing, coding, scoring, dan tabulating dan analisa data menggunakan pendekatan distribusi frekuensi dengan pendekatan logika.

Berdasarkan hasil penelitian didapatkan sikap remaja putri tentang deteksi dini kanker payudara dengan SADARI adalah bersikap negatif sebanyak 49 responden (53\%), dan bersikap positif sebanyak 43 responden (47\%).

Kesimpulan dari penelitian ini adalah sikap remaja putri tentang deteksi dini kanker payudara dengan SADARI adalah bersikap negatif.
\end{abstract}

\section{Kata Kunci :Sikap, SADARI, Remaja Putri \\ PRINCESS ADOLESCENT ABOUT EARLY DETECTION OF BREAST CANCER WITH SELF}

The lack of awareness of Indonesian women in conducting early detection of breast cancer, even many Indonesian women do not yet know how to detect breast cancer early which is one of the causes of breast cancer incidence is quite large apart from unhealthy lifestyle factors. A simple examination to detect changes in the breast that occur early is to examine the breasts themselves or referred to as conscious. The purpose of the study is to identify the attitudes of young women about early detection of breast cancer with breast selfexamination. Preliminary study conducted at SMAN 1 Pangkalan Bun.

The research design is descriptive. The population of young women in class $X$ and XI of SMAN 1 Pangkalan Bun, Kotawaringin Barat Regency, Central Kalimantan Province is 92 people with a sample of 92 respondents. The sampling technique uses total sampling. The variables are the attitudes of young women 
about early detection of breast cancer with BSE, the instrument used in this study was a questionnaire, with data processing through the stages of editing, coding, scoring, and tabulating and analyzing data using a frequency distribution approach with a logic approach.

Based on the results of the study found the attitudes of young women about the early detection of breast cancer with BSE is negative attitude of 49 respondents (53\%), and positive attitude of 43 respondents (47\%).

The conclusion of this study is the attitude of young women about early detection of breast cancer with BSE is negative.

Keywords: Attitude, Of Breast Cancer With Self, Teen Age

\section{PENDAHULUAN}

Kanker payudara bukan penyakit menular, tetapi merupakan salah satu penyakit menakutkan bagi kaum wanita. Pengobatan terbaik tersedia, tetapi perjuangan melawan kanker payudara tidak selalu berhasil. Hal itu dikarenakan pengetahuan kaum wanita akan kanker payudara masih sangat rendah, serta kurangnya kesadaran wanita dalam melakukan deteksi dini. Banyaknya kaum wanita yang belum menyadari pentingnya melakukan pemerikasaan pada payudaranya sendiri karena mereka menganggap kanker adalah hal yang serius dan tidak diketahui oleh dirinya sendiri.

Data dari WHO tahun 2007-2011 tercatat kasus baru penderita kanker payudara 124,5 dari 100.000 wanita per tahun dan angka kematian 22,6 dari 100.000 wanita per tahun. Berdasarkan data Sistem Informasi Rumah Sakit (SIRS) tahun 2010, kanker payudara dan kanker leher rahim merupakan jenis kanker tertinggi pada pasien rawat inap maupun rawat jalan di seluruh rumah sakit di Indonesia. Jumlah pasien kanker payudara sebanyak 12.014 orang dan kanker leher rahim sebanyak 5.249 orang.
Data dinas kesehatan kalimantan tengah mencatat yang menderita kanker payudara sebanyak 1527 orang untuk rawat jalan dan 898 orang untuk rawat inap. Data tahunan Dinas Kesehatan kalimantan tengah dari 34 puskesmas yang ada di Kabupaten kotawaringin barat terdapat 6 puskesmas yang terdeteksi kanker payudara diantaranya dari puskesmas madurejo sebanyak 6 orang, puskesmas arsel 6 orang, puskesmas natai pelingkau 4 orang, puskesmas pangkalan lada 4 orang, puskesmas pangkalan tiga 2 orang, dan puskesmas kumai 2 orang yang terdeteksi kanker payudara (Dinkes,2011). Ditemukan adanya 1 susp. Fibroadenoma mammae pada tahun 2019 di SMAN 1 Pangkalan Bun.

Berdasarkan studi pendahuluan pada 10 November 2019 di SMAN 1 Pangkalan Bun, dari 10 remaja putri yang diwawancarai 2 yang menyikapi positif untuk mau melakukan SADARI dan 8 yang menyikapi negatif untuk tidak melakukan SADARI. Bersadarkan latar belakang diatas maka peneliti tertarik untuk mengetahui seberapa berminatnya remaja tersebut dalam mengetahui bagaimana kondisi tubuhnya yang normal dengan melakukan sadari.

Dari uraian diatas, peneliti tertarik untuk meneliti dengan tentang "Sikap Remaja 
Putri tentang Deteksi Dini Kanker Payudara dengan SADARI". Rumusan masalah dalam penelitian ini adalah bagaimana sikap remaja putri tentang melakukan deteksi dini kanker payudara dengan SADARI. Tujuan dilakukan penelitian ini adalah untuk mengidentifikasi sikap remaja putri tentang melakukan deteksi dini kanker payudara dengan SADARI.

Manfaat dilakukannya penelitian ini adalah secara teoritis hasil penelitian ini dapat digunakan sebagai media informasi bagi remaja putri untuk merubah perilaku remaja putri tentang pentingnya mendeteksi dini kanker payudara dengan SADARI. Manfaat secara praktis bagi peneliti adalah hasil studi ini akan menambah pengetahuan dan pengalaman serta memperluas wawasan bagi peneliti tentang sikap remaja putri tentang deteksi dini kanker payudara dengan SADARI. Bagi siswa adalah dengan hasil penelitian ini diharapkan siswa dapat mengerti bahwa SADARI itu penting. Bagi sekolah adalah hasil penelitian ini diharapkan dapat menambah masukan atau informasi tentang pentingnya dilakukan deteksi dini kanker payudara dengan SADARI.

\section{BAHAN DAN METODE}

Penelitian ini tempat atau lokasi yang digunakan sebagai objek penelitian adalah kelas $\mathrm{X}$ dan XI di SMAN 1 pangkalan bun kabupaten kotawaringin barat provinsi kalimantan tengah.

Dalam penelitian ini jenis penelitian yang digunakan adalah penelitian deskriptif. Penelitian deskriptif adalah penelitian yang hanya menggambarkan suatu objek. Penelitian deskriptif yaitu suatu metode penelitian yang di arahkan untuk mendiskipsikan atau menguraikan suatu keadaan di dalam suatu penelitian komunitas atau masyarakat (Notoatmodjo, 2010).

Populasi adalah keseluruhan objek penelitian atau objek yang diteliti tersebut adalah populasi penelitian (Notoatmodjo, 2010). Pada penelitian ini populasinya adalah semua remaja putri kelas X dan XI di SMAN 1 pangkalan bun kabupaten kotawaringin barat provinsi kalimantan tengah sejumlah 92 responden. Teknik sampling merupakan suatu proses seleksi sampel yang digunakan dalam penelitian dari populasi yang ada, sehingga jumlah sampel akan mewakili keseluruhan populasi yang ada (Alimul,2012).

Teknik sampling yang digunakan adalah total sampling yang menggunakan seluruh populasi. Sampel merupakan bagian populasi yang akan diteliti atau sebagian jumlah dari karakteristik yang dimiliki oleh populasi (Alimul, 2012) Sampel dalam penelitian ini adalah semua remaja putri kelas $\mathrm{X}$ dan XI di SMAN 1 pangkalan bun kabupaten kotawaringin barat provinsi kalimantan tengah sebanyak 92 responden.

Variabel mengandung pengertian ukuran atau ciri yang dimiliki oleh anggotaanggota suatu kelompok yang berbeda dengan yang dimiliki oleh kelompok lain (Notoatmodjo, 2010). Pada penelitian ini variabelnya adalah sikap remaja putri tentang SADARI. Definisi operasional adalah mendefinisikan variable secara operasional berdasarkan karakteristik yang diamati, memungkinkan peneliti untuk melakukan observasi atau pengukuran secara cermat terhadap suatu objek atau fenomena (Alimul, 2012). Definisi operasional ada untuk memberikan batasan pengertian variabel yang akan 
diteliti. Definisi operasional dapat dilihat ada tabel 4.1 sebagai berikut.

Tabel 4.1 Definisi Operasional Sikap Remaja Putri tentang Deteksi Dini Kanker Payudara dengan SADARI

\begin{tabular}{|c|c|c|c|c|c|}
\hline $\begin{array}{c}\text { Variabel } \\
\text { Penelitia } \\
n\end{array}$ & $\begin{array}{c}\text { Definisi } \\
\text { Operasional }\end{array}$ & Parameter & $\begin{array}{l}\text { Alat } \\
\text { Ukur }\end{array}$ & $\begin{array}{l}\text { Skal } \\
\text { a } \\
\text { ukur }\end{array}$ & Skor/Kriteria \\
\hline $\begin{array}{l}\text { Sikap } \\
\text { remaja } \\
\text { putri } \\
\text { tentang } \\
\text { deteksi } \\
\text { dini } \\
\text { kanker } \\
\text { payudar } \\
\text { a } \\
\text { dengan } \\
\text { SADARI }\end{array}$ & $\begin{array}{l}\text { Reaksi atau } \\
\text { respon dari } \\
\text { remaja putri } \\
\text { tentang } \\
\text { deteksi dini } \\
\text { kanker } \\
\text { payudara } \\
\text { dengan } \\
\text { SADARI }\end{array}$ & $\begin{array}{l}\text { 1. Kogniti } \\
\text { f } \\
\text { 2. Afektif } \\
\text { 3. Konatif }\end{array}$ & $\begin{array}{l}K \\
U \\
E \\
S \\
I \\
O \\
N \\
E \\
R\end{array}$ & $\begin{array}{l}\text { O } \\
R \\
D \\
\text { I } \\
N \\
A \\
L\end{array}$ & $\begin{array}{l}\text { Skor positif : } \\
\text { SS : } 4 \\
\text { S : } 3 \\
\text { TS : } 2 \\
\text { STS : } 1 \\
\text { Skor negatif : } \\
\text { SS }: 1 \\
\text { S }: 2 \\
\text { TS : } 3 \\
\text { STS : } 4 \\
\text { Kriteria : } \\
\text { Sikap } \\
\text { responden } \\
\text { positif, bila T } \\
\text { responden > } \\
\text { T mean. } \\
\text { Sikap } \\
\text { responden } \\
\text { negatif, bila T } \\
\text { responden < } \\
\text { T mean. }\end{array}$ \\
\hline
\end{tabular}

Instrument penelitian adalah alat-alat yang akan digunakan untuk pengumpulan data (Notoatmodjo, 2010). Dalam penelitian ini instrumen yang digunakan adalah kuesioner tertutup atau berstruktur dimana kuesioner dibuat sedemikian rupa sehingga responden hanya tinggal memilih atau menjawab pada jawaban yang sudah ada (Alimul, 2012). Instrumen penelitian menggunakan kuesioner yang mewakili tiga parameter sikap yaitu kognitif, afektif dan konatif, dan menggunakan skala likert untuk skoring. Skala likert yang mana untuk pertanyaan favourable (positif) SS: 4, S: 3, TS: 2, STS: 1 dan sebaliknya pada pernyataan unfavourable (negatif) SS: 1, S: 2, TS: 3, STS: 4.

Teknik pengumpulan data dengan mendapatkan ijin dari Ketua STIKes BCM Pangkalan Bun dan Kepala Sekolah SMAN 1 Pangkalan Bun Kabupaten Kotawaringin Barat Provinsi $\begin{array}{lll}\text { Kalimantan } & \begin{array}{c}\text { Tengah, } \\ \text { pendekatan }\end{array} & \text { peliti } \\ \text { dengan }\end{array}$ responden untuk mendapatkan persetujuan dari responden sebagai subjek penelitian. Cara pengambilan data dengan menggunakan kuesioner yang dibagikan kepada responden, kemudian diambil oleh peneliti dan mengoreksi apakah semua soal pada lembar sudah diisi oleh responden.

\section{HASIL}

Data Umum

Karakteristik Responden Berdasarkan Umur dikategorikan menjadi 4 yang dapat dilihat pada tabel 5.1 sebagai berikut.

Tabel 5.1 Distribusi Frekuensi

Karakteristik Responden

Berdasarkan Usia di Kelas X dan XI SMAN 1 Pangkalan

Bun Kabupaten

Kotawaringin Barat Provinsi

Kalimantan Tengah Tahun 2019

\begin{tabular}{cccc}
\hline No & Umur & Frekuensi & Prosentase \\
\hline 1 & 16 tahun & 46 & $50 \%$ \\
2 & 17 tahun & 40 & $43 \%$ \\
3 & 18 tahun & 6 & $7 \%$ \\
4 & 19 tahun & 0 & $0 \%$ \\
\hline \multicolumn{2}{l}{ JUMLA } & 92 & $100 \%$ \\
H & &
\end{tabular}

Sumber : Data Primer, 2019

Berdasarkan tabel 5.1 sesuai karakteristik responden berdasarkan usia, dari 92 responden didapatkan setengahnya $(50 \%)$ usia responden adalah 16 tahun dan sebagian kecil usia responden adalah 18 tahun (7\%).

Karakteristik Responden Berdasarkan Pernah atau Tidak Pernah Mendapat Informasi mengenai SADARI dapat dilihat pada tabel 5.2 sebagai berikut. 


$\begin{array}{llr}\text { Tabel } & \text { 5.2 Distribusi } & \text { Frekuensi } \\ \text { Karakteristik Responden } & \text { Rerah atau } \\ \text { Berdasarkan Pernah } & \text { Tidak Pernah Mendapat } \\ \text { Informasi Tentang Deteksi } & \text { Dini Kanker Payudara } \\ \text { Dengan SADARI di Kelas X } \\ \text { dan XI SMAN 1 Pangkalan } \\ \text { Bun Kabupaten } \\ \text { Kotawaringin Barat Provinsi } \\ \text { Kalimantan Tengah Tahun } \\ 2019\end{array}$

\begin{tabular}{cccc}
\hline No. & Informasi & Frekuensi & Prosentase \\
\hline 1 & Pernah & 38 & $41 \%$ \\
2 & Tidak & 54 & $59 \%$ \\
& Pernah & & \\
\hline & JUMLAH & 92 & $100 \%$
\end{tabular}

Sumber : Data Primer, 2019

Berdasarkan tabel 5.2 didapatkan sesuai karakteristik pernah atau tidak pernah mendapat informasi mengenai SADARI, sebagian besar (59\%) responden tidak pernah mendapat informasi mengenai deteksi dini kanker payudara dengan SADARI dan hampir setengahnya (41\%) responden pernah mendapatkan informasi mengenai deteksi dini kanker payudara dengan SADARI.

\section{Data Khusus}

Sikap Remaja Putri Tentang Deteksi Dini Kanker Payudara Dengan SADARI di kategorikan menjadi 2 dapat dilihat pada tabel 5.4 sebagai berikut.

Tabel 5.4 Karakteristik Responden Berdasarkan Sikap Remaja Putri Tentang Deteksi Dini Kanker Payudara Dengan SADARI di Kelas X dan XI SMAN 1 Pangkalan Bun Kabupaten Kotawaringin Barat Provinsi Kalimantan Tengah Tahun 2019

\begin{tabular}{|c|c|c|c|}
\hline No & Sikap & $\begin{array}{c}\text { Frekuens } \\
\text { i }\end{array}$ & $\begin{array}{c}\text { Prosentas } \\
\mathrm{e}\end{array}$ \\
\hline 1 & Positif & 43 & $47 \%$ \\
\hline 2 & Negatif & 49 & $53 \%$ \\
\hline & $\begin{array}{c}\text { JUMLA } \\
\mathrm{H}\end{array}$ & 92 & $100 \%$ \\
\hline
\end{tabular}

Berdasarkan tabel 5.4 dapat menunjukkan sikap remaja putri tentang deteksi dini kanker payudara dengan SADARI sebagian besar (53\%) responden bersikap negatif dan hampir setengahnya (47\%) responden bersikap positif.

\section{PEMBAHASAN}

Berdasarkan hasil penelitian menunjukan bahwa sikap remaja putri tentang deteksi dini kanker payudara dengan SADARI bersikap negatif sebagian besar 49 (53\%) dan yang bersikap positif hampir setengah 43 (47\%). Sebaran distribusi sikap di dapatkan dari 3 parameter yaitu kognitif, afektif, konatif, dimana nilai kognitif sejumlah 2,70, afektif sejumlah 2,64, konatif sejumlah 2,72. Berdasarkan tabulasi sebaran parameter tersebut didapatkan paling rendah adalah afektif sedangkan yang paling baik konatif dan nilai rata-rata adalah kognitif. Dari ketiga parameter tersebut bagaimana pentingnya diantara ketiga parameter tersebut parameter afektif mendapatkan nilai yang paling rendah padahal parameter tersebut dasar untuk mewujudkan sikap. Pada parameter afektif terdiri dari pertanyaan yang distribusi menjadi favorable anvarorabel. Berdasarkan hasil penelitian faktor umur mempengaruhi terbentuknya prilaku baik positif maupun negatif. 
Berdasarkan tabel 5.1 menunjukan bawah sebagian responden umur 16 tahun yang termasuk remaja pertengahan sebanyak 57 orang (62\%).

Menurut peneliti faktor umur mempengaruhi terbentuknya afektif baik positif maupun negatif, banyaknya perilaku negatif tentang sikap remaja putri tentang deteksi dini kanker payudara dengan SADARI. Kemampuan seseorang dalam berfikir dapat dilihat dari umur seseorang, semakin dewasa seseorang maka semakin banyak informasi maupun pengalaman yang diperoleh, sebagaian besar remaja masih berperilaku negative terutama dalam melakukan deteksi dini kanker payudara dengan SADARI. Remaja putri yang mau melakukan deteksi dini kanker payudara sendiri bisa memungkinkan mengurangi angka penderita kanker payudara yang terus meningkat dari tahun ke tahun. Kanker payudara yang stadiumnya masih tergolong belum parah atau masih dalam tingkat tumor yang terdeteksi lebih awal pastinya akan bisa disembuhkan lebih awal, dari sebaran pertanyaan tersebut didapatkan pernyataan yang paling masalah adalah tentang pernyataan bahwa SADARI tidak harus dilakukan pada wanita hamil dan wanita yang telah mengalami rekonstruksi payudara. Kebanyakan remaja memang kesulitan untuk mengerti bahwa sebenarnya penting sekali untuk wanita hamil dan wanita yang telah mengalami rekonstruksi payudara untuk melakukan SADARI agar bisa menghindarkan kanker tersebut muncul atau muncul kembali padsa wanita yang telah merekonstruksi payudaranya. Dapat disimpulkan bahwa sebagian besar remaja memliki perilaku yang negative akan tetapi, dari pertanyaan tersebut rata-rata responden menyatakan cenderung setuju.

Responden dengan umur 16-19 tahun cara berfikirnya masih labil dan belum mempunyai pendirian sehingga pengetahuan yang dimiliki masih dalam kategori kurang sehingga mempengaruhi remaja bersikap negatif menurut teori Notoadmojo (2010). Remaja sering memperhatikan perilaku yang berubahubah. Pada suatu waktu tampak bertanggung jawab, tetapi dalam waktu lain tampak masa bodoh dan tidak bertanggung jawab. Remaja merasa cemas akan perubahan dalam dirinya. Perilaku demikian menunjukkan bahwa dalam diri remaja terdapat konflik yang memerlukan pengertian dan penanganan yang bijaksana (Eny Kusmiran, 2011).

Parameter konatif mendapatkan nilai yang paling tinggi parameter tersebut dasar untuk perilaku mewujudkan sikap positif tersebut. Pada parameter konatif terdiri dari pertanyaan yang distribusi menjadi positif dan negatif. Dari sebaran pertanyaan tersebut didapatkan pertanyaan yang paling tinggi jawaban setuju pada pernyataan pemeriksaan SADARI dengan menggunakan beberapa jari tangan yang dirapatkan, datar dan bersamaan sentuhan halus, hal ini sangat baik karena remaja juga harus berpikiran positif bahwa dalam melakukan SADARI dengan jari tangan yang dirapatkan akan memudahkan untuk mendeteksi bila adanya kelainan atau ketidaknormalan pada payudara, dengan berpikiran positif tersebut maka remaja akan sadar agar tidak membiarkan pengaruh negatif.

Menurut penelitian pernyataan pemeriksaan SADARI dengan menggunakan beberapa jari tangan yang dirapatkan, datar dan bersamaan 
sentuhan halus adalah cara yang digunakan untuk melakukan SADARI berdasarkan hasil penelitian mungkin dipengaruhi faktor sumber informasi yang didapat, fenomena yang ada saat ini adalah remaja lebih senang mencari informasi dari temannya dibandingkan dari media cetak atau tenaga kesehatan, alasan remaja karena teman lebih mudah untuk mencari informasi dan bertukar pikiran. Peran guru sebagai sumber informasi bagi remaja saat disekolah yang akan memberikan pengetahuan atau penyuluhan bagi remaja tersebut sangatlah penting. Informasi yang baik adalah informasi yang dapat diserap oleh remaja serta dapat diaplikasikan pada saat yang tepat, dengan informasi yang diperoleh remaja, maka informasi yang diterima akan mendorong remaja untuk melakukanya dalam kehidupan seharihari. Informasi merupakan hal yang sangat penting, dimana semakin banyak informasi yang di dapat tentang deteksi dini kanker payudara dengan SADARI maka akan mampu mengarahkan keinginan seseorang untuk melakukan dan mengaplikasikan tentang cara melakukan deteksi dini dengan SADARI.

Hal ini sesuai dengan Azwar (2007) media massa atau sumber informasi merupakan sarana komunikasi yang membawa pesan-pesan yang mengarahkan opini seseorang terhadap suatu masalah atau kejadian. Informasi juga merupakan salah satu faktor yang berperan dalam membentuk pemahaman atau persepsi seseorang. Pemberian informasi akan meningkatkan pengetahuan dan pengalaman yang dapat menambah kesadaran untuk berperilaku sesuai dengan pengetahuan dan pengalaman yang dimiliki (Kartono, 2006). Informasi memberikan pengaruh pada seseorang meskipun seseorang mempunyai pendidikan yang rendah, tetapi jika dia mendapatkan informasi yang baik dari berbagai media, maka hal ini akan dapat meningkatkan pengetahuan dan pengalaman seseorang. Memberikan informasi tentang mencapai cara-cara hidup sehat dan sebagainya akan meningkatkan pengetahuan masyarakat. Pada tahap selanjutnya pengetahuannya akan menumbuhkan kesadaran dan pada akhirnya akan menyebabkan orang berperilaku sesuai dengan pengetahuan yang dimilikinya. Hasil atau perubahan yang dicapai akan bersifat langgeng karena didasari pada kesadaran mereka sendiri dan bukan paksaan (Notoatmodjo, 2007).

Parameter konatif ini merupakan aspek kecenderungan berperilaku tertentu sesuai dengan sikap yang dimiliki oleh seseorang, dan berisi tendensi atau kecenderungan untuk bertindak / beraksi terhadap sesuatu dengan cara-cara tertentu. Berkaitan dengan objek yang dihadapi adalah logis untuk mengharapkan bahwa sikap seseorang adalah dicerminkan dalam bentuk tendensi perilaku. Perilaku baik merupakan hal yang positif dan perilaku buruk merupakan hal yang negatif. Pada parameter ini sebaran pertanyaan tersebut didapatkan yang paling rata-rata jawaban tidak setuju pada pernyataan kekuatan tekanan berbeda-beda dalam melakukan SADARI, padahal hal tersebut turut berperan dalam mendeteksi kanker payudara.

Sikap manusia selalu berubah, sebagaian perubahan itu disebabkan karena kejadian alamiah, atau memang direncanakan sendiri oleh subjek, serta memang ada kesediaan untuk berubah, agar perubahan tersebut terlaksana maka 
diperlukan dukungan atau motivasi bagi remaja terutama dukungan dari lingkungn sekitar terutama orang tua dan kelompok kaum remaja, misalnya dengan cara berbagi informasi berupa pengalaman antar teman atau orang lain tentang kanker payudara dan cara pencegahan dengan deteksi dini dengan SADARI karena perubahan sikap seseorang dari pada mengadopsi pengetahuan dan perilaku dari teori saja. Pengalaman buruk yang pernah dialami oleh orang lain tersebut remaja akan berfikir hal yang mereka alami jangan sampai terjadi pada diri remaja atau hal buruk tersebut jangan sampai terulang kembali dengn pikiran tersebut maka para remaja bersedia untuk merubah sikap dalam mencegah kanker payudara dengan melakukan deteksi dini kanker payudara dengan SADARI.

\section{SIMPULAN DAN SARAN}

\section{Simpulan}

Berdasarkan hasil penelitian dan pembahasan dapat disimpulkan bahwa sikap remaja putri tentang deteksi dini kanker payudara dengan SADARI adalah bersikap negatif cenderung tidak mau melakukan SADARI.

\section{Saran}

Bagi Remaja

Bagi remaja karena pentingnya deteksi dini kanker payudara untuk menguragi angka kanker payudara diharapkan remaja putri mau untuk melakukan deteksi dini dengan SADARI.

Bagi Peneliti Selanjutnya

Diharapkan melakukan penelitian lebih lanjut lagi untuk perbaikan demi kesempurnaan dari hasil penelitian ini maka penulis berharap ada yang meneliti lebih lanjut mengenai sikap remaja putri tentang deteksi dini kanker payudara dengan SADARI.

\section{KEPUSTAKAAN}

A Wawan dan Dewi M, 2010. Pengetahuan, Sikap, dan Perilaku Manusia. Yogyakarta : Nuha Medika

Azwar, 2010. Sikap Manusia Teori dari Pengukurannya. Yogyakarta : Pustaka Pelajar

Azwar, Saifudin. 2011. Sikap Manusia Teori dan Pengukurannya. Yogjakarta : Pustaka Pelajar.

Desmita. 2010. Psikologi Perkembangan. Bandung : Rosdakarya

Hidayat, A. A. 2010. Metode

Penelitian Kebidanan dan Teknik Analisa Data. Jakarta : Salemba Medika.

Kumalasari, Intan. 2012. Kesehatan Reproduksi untuk Mahasiswa Kebidanan dan Keperawatan. Jakarta : Salemba Medika.

Kusmiran, 2011. Kesehatan Reproduksi Remaja dan Wanita. Jakarta : salemba Medika

Notoadmodjo, $\quad$ S. 2010. Metodologi Penelitian Kesehatan. Jakarta : Rineka Cipta.

Nursalam. 2003. Metodologi Penelitian Kesehatan. Jakarta : Rineka Cipta.

Nursalam. 2008. Konsep dan Penerapan Metodologi Penelitian Ilmu Keperawatan, Pedoman Skripsi, Tesis dan Instrumtan dan Penelitian Keperawatan. Jakarta : Salemba Medika.

Pamungkas, Zaviera. 2011. Deteksi Dini Kanker Payudara. Jogjakarta : Buku Biru.

Romauli, Suryati, SST dan Anna Vida Vindasari, SST. 2011. Kesehatan Reproduksi untuk Mahasiswa Kebidanan. Yogjakarta : Nuha Medika. 
Sarwono, S. 2011. Psikologi

Remaja. Jakarta : Rajawali Pers.

Saryono, Roischa Dyah

Pramitasari. 2009. Perawatan Payudara.

Yogyakarta : Nuha Medika

Saryono. 2010. Metodologi Penelitian Kebidanan D III, D IV, S I, dan S 2. Yogjakarta : Nuha Medika.

Yusuf, S. 2011. Psikologi Perkembangan Anak dan Remaja. Bandung : Rosdakarya.

Zulkifli, 2009. Psikologi

Perekembangan. Bandung : PT Remaja

Rosda Karya. 